\title{
Effect of Formamide in the Leuckart Reaction
}

\author{
Tore Lejon* and Irene Helland
}

Faculty of Science, Department of Chemistry, University of Troms $\varnothing$, N-9037 Troms $\emptyset$, Norway

Lejon, T. and Helland, I., 1999. Effect of Formamide in the Leuckart Reaction.

Acta Chem. Scand. 53: 76-78. (C) Acta Chemica Scandinavica 1999.

Reductive amination of carbonyl compounds with ammonium salts of formic acid or with formamide, known as the Leuckart reaction, was first reported in $1885 .^{1}$ Modifications to the original reaction were first published by Wallach and co-workers, ${ }^{2}$ but it was work by the group of Ingersoll ${ }^{3}$ that led to reaction conditions that could serve for preparative purposes. A useful method for the methylation of amines using formaldehyde as the reactant containing the carbonyl functionality is the Eschweiler-Clarke procedure. ${ }^{4}$ The reaction and the modifications have been discussed in review articles ${ }^{5}$ and there are also articles discussing the mechanism. ${ }^{6}$

Recent work dealing with the Leuckart reaction was published by Carlson et al., ${ }^{7}$ who showed that the addition of water to the mixture of ketone and formamide led to higher yields and better reproducibility, and by Bianchini and co-workers ${ }^{8}$ who have used spectroscopic methods to prove a radical mechanism for the reduction of the initially formed (form)imide to (form)amide.

In a project carried out in our laboratory involving the use of different amines, it was decided to use the new optimised reaction conditions for the synthesis of starting materials. Surprisingly it was found that yields were lower than expected and were highly variable, and apparently independent of the carbonyl compound. The only variable that could be identified as differing from the optimised procedure was the brand of formamide, and it was therefore decided to look once more into what controls the course of the reaction. Acetophenone was chosen as the carbonyl compound in order to compare the results with the earlier study. As a simplification, it was decided to analyse the yield of $N$-(1-phenylethyl)formamide (Scheme 1) by GLC instead of analysing the hydrolysed amine.

\section{Results and discussion}

Five different brands of formamide were chosen for the study. Based on earlier experience it was decided to use a larger excess of the formamide, all other variables being as in the optimised procedure. As can be seen from Table 1, the yields vary considerably between experiments, but in none of them is the yield comparable to those obtained earlier. Experiments using different acetophenones were undertaken but yields were still only affected by what brand of formamide was used.

A screening procedure ${ }^{9}$ with the settings of the experimental variables at two levels was then employed with the range of variation given within brackets: amount of water [no water/water added], and reaction temperature $\left[165^{\circ} \mathrm{C} / 205^{\circ} \mathrm{C}\right]$. The results are summarised in Table 2 .

Table 1. Yield of $\mathrm{N}$-(1-phenylethyl)formamide using previously reported optimum conditions with water added [acetophenone/water (w/w), 2.5)]. ${ }^{7}$

\begin{tabular}{lll}
\hline & $T /{ }^{\circ} \mathrm{C}$ & Yield $(\%)$ \\
\hline Aldrich & 205 & 75.5 \\
Baker & 205 & 76.4 \\
Fischer & 205 & 68.3 \\
Fluka & 205 & 73.3 \\
Merck & 205 & 60.0 \\
\hline
\end{tabular}

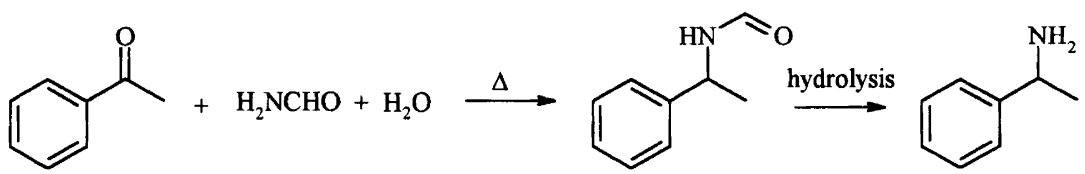

Scheme 1.

*To whom correspondence should be addressed. 
Table 2. Yield of $\mathrm{N}$-(1-phenylethyl)formamide as a function of temperature and added water.

\begin{tabular}{lcllll}
\hline & $T /{ }^{\circ} \mathrm{C}$ & Water & Yield (\%) & Water $^{a}$ & Yield (\%) \\
\hline Aldrich & 165 & No & 58.3 & Yes & 70.1 \\
Baker & 165 & No & 16.0 & Yes & 69.8 \\
Fischer & 165 & No & 57.0 & Yes & 72.2 \\
Fluka & 165 & No & 40.8 & Yes & 65.0 \\
Merck & 165 & No & 62.0 & Yes & 62.8 \\
Aldrich & 205 & No & 10.5 & Yes & 75.5 \\
Baker & 205 & No & 15.3 & Yes & 76.4 \\
Fischer & 205 & No & 6.9 & Yes & 68.3 \\
Fluka & 205 & No & 33.9 & Yes & 73.3 \\
Merck & 205 & No & 18.7 & Yes & 60.0 \\
\hline
\end{tabular}

${ }^{a}$ Acetophenone/water (w/w), 2.5 .

From this table a few points are notable: $i$, in the absence of water (all other factors being similar), yields vary depending on formamide used; ii, in the absence of water, yields are inversely proportional to temperature; iii, the second effect disappears when the reaction is run in the presence of water.

Although yields were less variable when water was added to the reaction mixture and a lower temperature was used, yields were still not as high as after the earlier optimisation. A new series of experiments was performed were the temperature was kept at the lower level and the amount of water added was varied. The results are shown in Table 3.

As is clearly seen from the table, yields vary with the brand of formamide used if the other variables are kept the same. Yields in excess of $90 \%$ can be obtained with all brands of formamide, except the one obtained from Baker.

Table 3. Yield of $N$-(1-phenylethyl)formamide as a function of amount of added water.

\begin{tabular}{llll}
\hline & $T /{ }^{\circ} \mathrm{C}$ & Water $/ \mathrm{ml}$ & Yield $(\%)$ \\
\hline Aldrich & 165 & $0.3^{a}$ & 70.1 \\
& 165 & $0.5^{b}$ & 94.2 \\
& 165 & $0.7^{c}$ & 95.5 \\
Baker & 165 & 0.3 & 69.8 \\
& 165 & 0.5 & 83.2 \\
Fischer & 165 & 0.7 & 85.4 \\
& 165 & 0.3 & 72.2 \\
Fluka & 165 & 0.5 & 84.4 \\
& 165 & 0.7 & 95.9 \\
& 165 & 0.3 & 65.0 \\
Merck & 165 & 0.5 & 99.4 \\
& 165 & 0.7 & 88.4 \\
& 165 & 0.3 & 62.8 \\
& 165 & 0.5 & 91.1 \\
\hline
\end{tabular}

${ }^{a}$ Acetophenone/water $(w / w), \quad 2.5$. ${ }^{b}$ Acetophenone/water $(w / w), 1.5 .{ }^{c} A c e t o p h e n o n e / w a t e r(w / w), 1.07$.

\section{Experimental}

Analytical scale. Acetophenone $(0.75 \mathrm{~g})$ and formamide $(3.75 \mathrm{~g})$ were magnetically stirred in a $50 \mathrm{ml}$ roundbottomed flask fitted with a reflux condenser. When the reactions were run without the addition of water, a guard tube containing calcium chloride was placed in the top of the condenser. The flask was immersed in an oil-bath and heated to the desired temperature. Heating overnight was followed by addition of $10 \mathrm{ml}$ of water and extraction of the aqueous phase with $3 \times 10 \mathrm{ml}$ of diethyl ether. The combined ethereal phases were dried over magnesium sulfate and a $3 \mathrm{ml}$ sample of the solution was then added to approximately $45 \mathrm{mg}$ of phenylcyclohexane internal standard and the mixture was analysed by GLC.

Preparative scale. Acetophenone (Fluka) (4.5 g), formamide (Aldrich) $(20 \mathrm{ml})$ and water $(3.6 \mathrm{ml})$ were stirred in a $100 \mathrm{ml}$ round-bottom flask fitted with a reflux condenser. The flask was immersed in an oil-bath and maintained at $165^{\circ} \mathrm{C}$ overnight. The reaction mixture was cooled, after which $30 \mathrm{ml}$ of water were added and the solution was extracted with $50 \mathrm{ml}$ diethyl ether. The aqueous layer was neutralised by addition of solid sodium carbonate and further extracted with two $50 \mathrm{ml}$ portions of diethyl ether. The combined ethereal solutions were washed with saturated sodium bicarbonate and brine and dried over $\mathrm{MgSO}_{4}$. Solvent removal afforded $4.7 \mathrm{~g}$ $(84.1 \%)$ of an orange oil. Further extraction with $50 \mathrm{ml}$ ethyl acetate gave (after drying and solvent removal) an additional $0.7 \mathrm{~g}$, giving a total of $5.4 \mathrm{~g}(96.5 \%)$. Bulb-tobulb distillation left $5.12 \mathrm{~g}$ of a colourless material (containing traces of formamide) that partially solidified upon standing.

Starting material. The aceptophenone used was either from Aldrich ( $99 \%$ ) or Fluka (p.a.). Formamides used: Aldrich (97\%), Baker (p.a.), Fisher (>99\%), Fluka (purum) or Merck (p.a.). Phenylcyclohexane was from Aldrich (96\%).

Instrumentation. The gas chromatograph used was a Varian 3400 fitted with a $15 \mathrm{~m}, 0.32$ i.d. SPB-5 column supplied by Supelco.

\section{References}

1. Leuckart, R. Ber. Dtsch. Chem. Ges. 18 (1885) 2341.

2. (a) Wallach, O. Ber. Dtsch. Chem. Ges. 24 (1891) 3994; (b) Wallach, O. and Griepenkerl, J. Justus Liebigs Ann. Chem. 269 (1892) 347; (c) Wallach, O. Justus Liebigs Ann. Chem. 272 (1893) 99; (d) Wallach, O. Justus Liebigs Ann. Chem. 276 (1893) 296; (e) Wallach, O. Justus Liebigs Ann. Chem. 289 (1896) 338; (f) Wallach, O. Justus Liebigs Ann. Chem. 300 (1898) 282; (g) Wallach, O., Hüttner, K. and Altenburg, J. Justus Liebigs Ann. Chem. 343 (1905) 54

3. (a) Ingersoll, A. W., Brown, J. H., Kim, C. K., Beauchamp, W. D. and Jennings, G. J. J. Am. Chem. Soc. 58 (1936) 1808; (b) Ingersoll, A. W. Org. Synth. Coll. Vol. 2 (1943) 503. 4. (a) Eschweiler, W. Ber. Dtsch. Chem. Ges. 38 (1905) 880; 
(b) Clarke, H. T., Gillespie, H. B. and Weisshaus, S. Z. J. Am. Chem. Soc. 58 (1933) 4571; (c) Spialter, L. and Pappalardo, J. A. The Aliphatic Tertiary Amines, McMillan, New York 1965, p. 45ff.

5. (a) Moore, M. L. Org. React. 5 (1949) 301; (b) Möller, E. and Schröter, R. In Houben, W. Methoden der organischen Chemie, Vol. XI/1 (1957) 648.

6. (a) Lukasiewicz, A. Tetrahedron 19 (1963) 1789; (b) Bach, R. D. J. Org. Chem. 33 (1968) 1647; (c) Semenov, V. A. and Skorovarov, D. I. Zh. Org. Khim. 5 (1969) 41; (d) Davis, M., Parnell, E. W. and Rosenbaum, J. J. Am. Chem. Soc., Perkin Trans. I (1972) 1420; Breucr, E. and Melumad, D. J. Org. Chem. 37 (1972) 3949.
7. Carlson, R., Lejon, T., Lundstedt, T. and Le Clouerec, E. Acta Chem. Scand. 47 (1993) 1046.

8. Bianchini, R., Forte, C., Musumarra, G., Pinzino, C. and Sergi, C. Tetrahedron 53 (1997) 6907.

9. For discussions of the principles see (a) Box, G. E. P., Hunter, W. G. and Hunter, J. S. Statistics for Experimenters, Wiley, New York 1978; (b) Carlson, R. Design and Optimization in Organic Synthesis, Elsevicr, Amsterdam 1992.

Received May 12, 1998. 